\title{
Assessment of humoral immunity to Eimeria tenella sporozoites in chickens by ELISA
}

\author{
S. Saravanan ${ }^{1}$, K. M. Palanivel ${ }^{1}$, T. J. Harikrishnan ${ }^{2}$, P. Srinivasan ${ }^{3}$ and G. Selvaraju ${ }^{1}$
}

1. Department of Veterinary Epidemiology and Preventive Medicine, Veterinary College and Research Institute, Tamil Nadu Veterinary and Animal Sciences University, Namakkal, Tamil Naud, India; 2. Department of Veterinary Parasitology, Veterinary College and Research Institute, Namakkal, Tamil Nadu, India; 3. Poultry Disease Diagnosis and Surveillance Laboratory, Veterinary College and Research Institute Campus, Namakkal, Tamil Nadu, India. Corresponding author: S. Sarvanan, email: sarvet_25@yahoo.com KMP: drkmpalanivel@gmail.com,TJH: hari@tanuvas.org.in, PS: srinipat2004@yahoo.com,GS: g.selvaraju@tanuvas.org.in Received: 09-04-2014, Revised: 29-05-2014, Accepted: 02-06-2014, Published online: 03-07-2014

doi: 10.14202/vetworld.2014.452-456

How to cite this article: Saravanan S, Palanivel KM, Harikrishnan TJ, Srinivasan P and Selvaraju G (2014) Assessment of humoral immunity to Eimeria tenella sporozoites in chickens by ELISA, Veterinary World 7(7): 452-456.

\begin{abstract}
Aim : To assess the humoral immune response of Eimeria tenella sporozoites in broiler chickens by a developed enzyme linked immunosorbent assay (ELISA) and the efficacy in terms of bodyweight, lesion score and oocysts excretion in immunized broilers.

Materials and Methods: Purified live E. tenella sporozoites were administered subcutaneously in neck region of broiler chickens in the early life (first week) at different concentrations. The potency of the sporozoite vaccine as assessed by $\mathrm{IgG}$ levels and the performance in immunized broilers as assessed by body weight, lesion score and oocysts excretion in faeces after challenge with 10,000 live E. tenella oocysts at 49 days of age were evaluated.

Results: The chickens of group (T4) immunized with $20 \mu \mathrm{g}$ of antigen on day 6 showed an increase in IgG levels $(0.161 \pm 0.004)$ two weeks post immunization (PI) peaking $(0.399 \pm 0.016)$ at 5 weeks PI. The mean weekly weight gain (g) after challenge, at 56 days of age was high in T4 (148 $\pm 4.751 \mathrm{~g})$ with a low mean lesion score $(2.5 \pm 0.22)$ and mean oocyst output (x10 ${ }^{3}$ oocytes per gram (OPG) in faeces (100.3 \pm 45.72$)$ when compared to unimmunised infected controls.

Conclusion: An early but partial immune response against caecal coccidiosis could be achieved by immunization with $E$. tenella specific sporozoites in chickens of less than a week old. Moreover, the performance of immunized chickens as indicated by weight gain, lesion score and oocyst output was found to be superior to the unimmunized infected controls.
\end{abstract}

Keywords: bodyweight, broiler chickens, Eimeria tenella sporozoites, ELISA, IgG levels, lesion score.

\section{Introduction}

Globally, India ranks fifth in chicken meat production with the value of poultry exports being around INR 4410 million during 2008-09 and the demand for chicken meat in next 2-3 decades is expected to increase many-folds very rapidly [1]. However, efficiency of broiler production today seems to be hampered by many diseases. Coccidiosis is one of those diseases that poses a considerable economic loss to broiler industry, with Eimeria tenella being one of the most prevalent species in India causing caecal or bloody type of coccidiosis associated with reduced growth rate, poor performance and mortality in broiler chickens [2]. The disease is responsible for $6-10 \%$ of all mortality in broilers [3] and in India, 95.61\% (INR 1089.17 million) of the total economic loss occurs due to the disease.

Prophylactic medication has been successfully used to control coccidiosis, however there is an increasing emergence of drug-resistance in commercial industry [4]. Numerous vaccination strategies have been attempted to manage avian coccidiosis [5]. However, the live

Copyright: The authors. This article is an open access article licensed under the terms of the Creative Commons Attribution License (http://creativecommons.org/licenses/by/2.0) which permits unrestricted use, distribution and reproduction in any medium, provided the work is properly cited. oocyst oral vaccines currently being used have limited utility in the broiler industry in view of reduced weight gain and recycling of oocysts in the litter resulting in coccidiosis outbreaks $[6,7]$ thus necessitating alternate immunological approaches to control the disease.

Hence, this study presents the assessment of potency of the sporozoite vaccine of $E$. tenella administered by parenteral route in broiler chickens to block the transmission via litter, by a developed enzyme linked immunosorbent assay (ELISA) and the efficacy in terms of bodyweight, lesion score and oocysts excretion in immunized broilers.

\section{Materials and Methods}

Ethical approval: The project proposal of the Ph.D. research programme to conduct this study was duly approved by Institutional Animal Ethics Committee of Veterinary College and Research Institute, Namakkal.

Experimental design: In this experimental trial, five groups of day old Cobb 400 broiler chicks were used $(\mathrm{n}=15$ per group) and purified sporozoite antigen was administered subcutaneously @ $0.1 \mathrm{ml}$ per bird in the neck region, to groups T1 to T4 and T5 was kept as control. The groups, T1 and T2 were administered 10 and $20 \mu \mathrm{g}$ of live sporozoite antigen, respectively on $2^{\text {nd }}$ day of age, and T3 and T4 were administered 10 and 20 


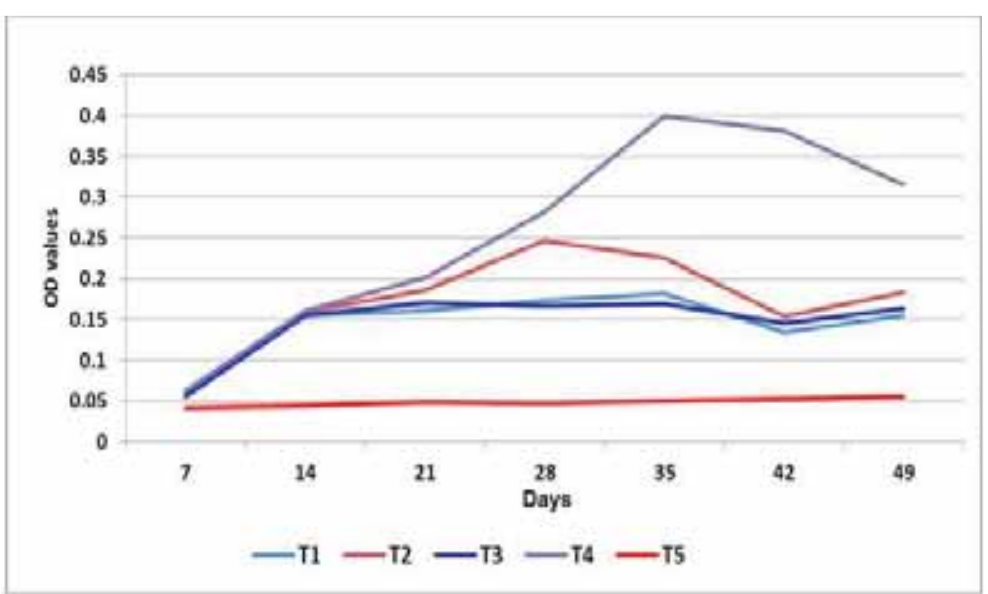

Figure-1: Mean ELISA IgG levels in chickens of experimental trial.

$\mu \mathrm{g}$ of live sporozoite antigen, respectively on $6^{\text {th }}$ day of age. The immune response of coccidian sporozoites vaccinated experimental birds were assessed by ELISA developed as per the recommended method [8] with minor modifications.

Protein estimation: Sporozoites of E. tenella $\left(3.6 \times 10^{5}\right)$, extracted and purified by DE-52 column chromatography were washed twice in $0.1 \mathrm{M}$ carbonate buffer ( $\mathrm{pH} 9.5$ ), resuspended in $1 \mathrm{ml}$ of carbonate buffer and shaked by vortexing for $5 \mathrm{~min}$ with $0.5 \mathrm{~mm} 50 \%$ glass beads. The optimal protein concentration was estimated by Lowrie method using a standard curve derived from bovine serum albumin and purified sporozoites of E. tenella.

Positive and negative sera: The E. tenella positive serum was obtained from the birds inoculated with 3000 E. tenella sporulated oocysts at 3 weeks of age followed by 5000 E. tenella sporulated oocysts at 6 weeks of age and after 21 days post inoculation, sera were collected. Negative serum samples were collected from unvaccinated control birds fed with coccidiostats.

ELISA procedure: The optimal dilution of coating antigen, sera and rabbit anti-chicken HRP conjugate were standardized by checker board titration and it was found that $1 \mu \mathrm{g} / \mathrm{well}$ of sporozoite antigen, 1:50 dilution of sera and 1:5000 dilution of peroxidase conjugated rabbit anti-chicken IgG (GeNei, Bengaluru) gave optimum results. Each well of a 96 well flat bottom microtitre plate was coated with $1 \mu \mathrm{g}$ of sporozoite antigen in $0.05 \mathrm{M}$ carbonate buffer (pH 9.6) and the plate was kept at $4^{\circ} \mathrm{C}$ overnight. The plate was washed with $0.05 \%$ PBS Tween-20 (PBST) three times and $100 \mu 1$ of $2 \%$ skim milk was added to each well to block unreacted sites in the wells. After incubation for $1 \mathrm{~h}$ at $37^{\circ} \mathrm{C}$, plate was washed three times with PBST and dried by tapping against the filter paper. Test positive and negative control sera were used in 1:50 dilution (in PBST) in triplicate and the plate was incubated for $1 \mathrm{~h}$ at $37^{\circ} \mathrm{C}$. After washing with PBST three times, rabbit anti-chicken IgG conjugated with peroxidase (Sigma ALdrich ,Bangalore, India) was used at 1: 5000 dilution in $100 \mu 1$ volume per well and each plate had one HRP control well. The plate was incubated for $1 \mathrm{~h}$ at $37^{\circ} \mathrm{C}$, washed again with PBST three times and substrate tetramethyl benzidine solution was added to all the wells in $100 \mu$ l volume, with a substrate control. The plate was incubated at room temperature for $30 \mathrm{~min}$ and $100 \mu 1$ stopping reagent (sulphuric acid) was added. The plate was then read in multiscan ELISA reader at $450 \mathrm{~nm}$ and the optical density (OD) value twice and above the negative OD was taken as cut off value (positive).

The potency of the sporozoite vaccine as assessed by IgG levels and efficacy as assessed by bodyweight, lesion score and oocysts excretion in faeces after challenge with 10,000 live E. tenella oocysts at 49 days of age were examined. The relative ratio of body weight gain was calculated from the following formula:

$\mathrm{A}=$ Mean weight gain / Mean weight at the end of experiment

$\mathrm{B}=$ Mean weight gain of negative control / Mean weight at the end of experiment

Relative ratio of weight gain $=\mathrm{A} / \mathrm{B} \times 100$

Statistical analysis: Statistical analysis was performed by randomized block design (Snedecor and Cochran) and analysis of variance (ANOVA two-way analysis) with SPSS statistical software (version 10.01).

\section{Results and Discussion}

The ELISA could be an useful technique in the assessment of potency of sporozoite vaccine as it has a high sensitivity and specificity of $100 \%$ in the detection of antisporozoite antibodies of Eimeria species in vaccination programmes and monitoring of infectivity [9]. In the experimental trial, the antibody levels ( $\operatorname{IgG})$ of all vaccinated groups at day 7 were significantly higher $(\mathrm{P}<0.05)$ than that of control group (Figure-1). The antibody level of T4 at 49 days of age was higher with a mean ELISA OD value of $0.316 \pm 0.016$ followed by T2 with a mean OD value of $0.183 \pm 0.004$ when compared to T5 $(0.056 \pm 0.003)$ and the antibody level was significantly different $(\mathrm{P}<0.01)$ from that of other vaccinated groups. However, at 49 days of age, the antibody levels of T1 (mean OD of $0.155 \pm 0.011$ ) and $\mathrm{T} 3$ (mean OD of $0.164 \pm 0.007$ ) administered with $10 \mu \mathrm{g}$ of antigen to different age groups did not differ 
Table-1: Mean O.D.values of ELISA in the $E$. tenella sporozoite immunized broiler chickens

\begin{tabular}{llllllll}
\hline Treatment & \multicolumn{7}{c}{ OD values ( Mean \pm SE) } \\
\cline { 2 - 8 } Groups & $\mathbf{7}^{\text {th }}$ day & $\mathbf{1 4}^{\text {th }}$ day & $\mathbf{2 1}^{\text {st }}$ day & $\mathbf{2 8}^{\text {th }}$ day & $\mathbf{3 5}^{\text {th }}$ day & $\mathbf{4 2}^{\text {nd }}$ day & $\mathbf{4 9}^{\text {th }}$ day \\
\hline T1 & $0.058^{\mathrm{bP}} \pm 0.004$ & $0.156^{\mathrm{BQ}} \pm 0.002$ & $0.161^{\mathrm{bQ}} \pm 0.004$ & $0.173^{\mathrm{BQ}} \pm 0.007$ & $0.182^{\mathrm{BQ}} \pm 0.023$ & $0.134^{\mathrm{BQ}} \pm 0.015$ & $0.155^{\mathrm{BQ}} \pm 0.011$ \\
T2 & $0.058^{\mathrm{bP}} \pm 0.003$ & $0.159^{\mathrm{BQR}} \pm 0.006$ & $0.186^{\mathrm{bcR}} \pm 0.003$ & $0.247^{\mathrm{CS}} \pm 0.011$ & $0.225^{\mathrm{BCS}} \pm 0.013$ & $0.154^{\mathrm{BQ}} \pm 0.007$ & $0.183^{\mathrm{CR}} \pm 0.004$ \\
T3 & $0.055^{\mathrm{bP}} \pm 0.003$ & $0.156^{\mathrm{BQR}} \pm 0.006$ & $0.171^{\mathrm{bcR}} \pm 0.003$ & $0.166^{\mathrm{BQR}} \pm 0.002$ & $0.169^{\mathrm{BQR}} \pm 0.010$ & $0.145^{\mathrm{BQ}} \pm 0.006$ & $0.164^{\mathrm{BCQR}} \pm 0.007$ \\
T4 & $0.062^{\mathrm{bP}} \pm 0.003$ & $0.161^{\mathrm{BQ}} \pm 0.004$ & $0.201^{\mathrm{CR}} \pm 0.016$ & $0.282^{\mathrm{DS}} \pm 0.005$ & $0.399^{\mathrm{CDS}} \pm 0.016$ & $0.382^{\mathrm{CS}} \pm 0.022$ & $0.316^{\mathrm{DS}} \pm 0.010$ \\
T5 & $0.042^{\mathrm{apq}} \pm 0.002$ & $0.044^{\mathrm{Apq}} \pm 0.003$ & $0.049^{\mathrm{Apq}} \pm 0.004$ & $0.047^{\mathrm{Apq}} \pm 0.002$ & $0.050^{\mathrm{Apq}} \pm 0.005$ & $0.053^{\mathrm{Apq}} \pm 0.002$ & $0.056^{\mathrm{Aq}} \pm 0.003$ \\
\hline
\end{tabular}

$\mathrm{T} 1$ and T2 - administered 10 and $20 \mu \mathrm{g}$ of live sporozoite antigen, respectively on 2nd day of age, and T3 and T4 were administered 10 and $20 \mu \mathrm{g}$ of live sporozoite antigen, respectively on 6th day of age.*Row-wise mean ( \pm SE) with different superscript (pqr...) differs significantly $(P<0.05)$, mean bearing 'upper case' superscript in a row is highly significant $(P<0.01)$. ${ }^{*}$ Column -wise mean $( \pm S E)$ with different superscript (abc...) differs significantly $(P<0.05)$, mean bearing 'upper case' superscript in a column is highly significant $(P<0.01)$.

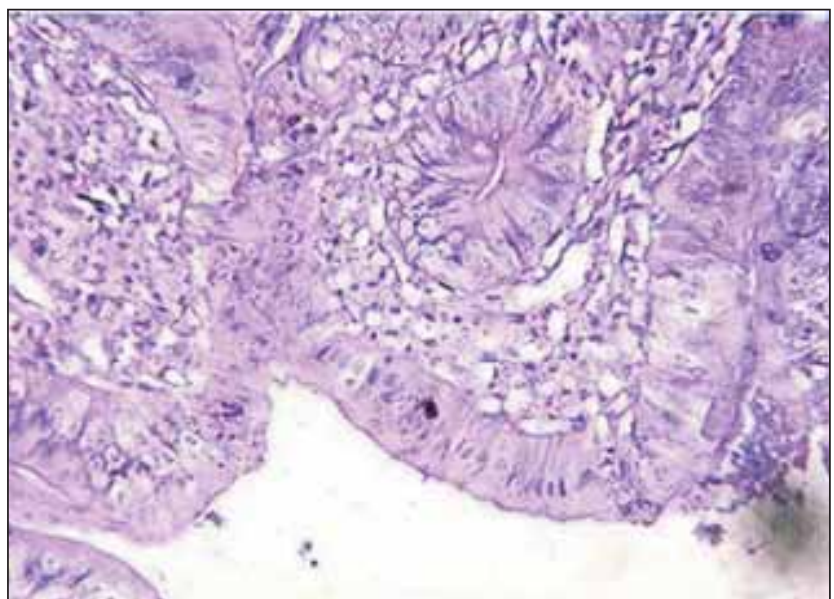

Figure-2: Group T4 showing stunting of villi in the caeca $(\mathrm{H}$ \& $E \times 400)$.

significantly $(\mathrm{P}>0.05)$. The antibody levels within all four vaccinated groups up to $49^{\text {th }}$ day of age differed significantly $(\mathrm{P}<0.01)$ from the control group (Table-1).

However, the humoral immune response (IgG) observed was high in T4 and T2 which differed significantly $(\mathrm{P}<0.01)$ from $\mathrm{T} 1$ and $\mathrm{T} 3$. Thereafter, the antibody levels of T1, T2, T3 and T4 rose on day 14 of age, peaked on $35,28,21$ and 35 days of age, respectively and declined thereafter on $42,35,28$, and 49 days of age, respectively. These findings are in accordance with Hasbullah et al. [10] who observed peak levels of $E$. tenella merozoite antibodies $(0.5$ to 1.0 OD) on 29 days post inoculation whereas, Constantinoiu et al. [8] observed a decline in E. tenella sporozoite antibody levels $(<2.0)$ after $42-49$ days of age. The peak antibody levels within the groups T4 and T2 were significantly high $(\mathrm{P}<0.01)$ when compared to antibody levels after day 7 and antibody levels in T1 and T3 but in groups T1 and T3, the peak antibody levels were not statistically significant $(\mathrm{P}>0.05)$ when compared to antibody levels after day 7 . Hence, there was a positive dose-response relationship among the vaccinated groups and the group T4 showed higher ELISA IgG levels than the other groups. The findings of the present study are in agreement with Kiani and Farhang [11] who observed increased antibody levels with an OD value of $0.303 \pm 0.001$ in comparison with the negative controls in chicks vaccinated with live sporozoites vaccine

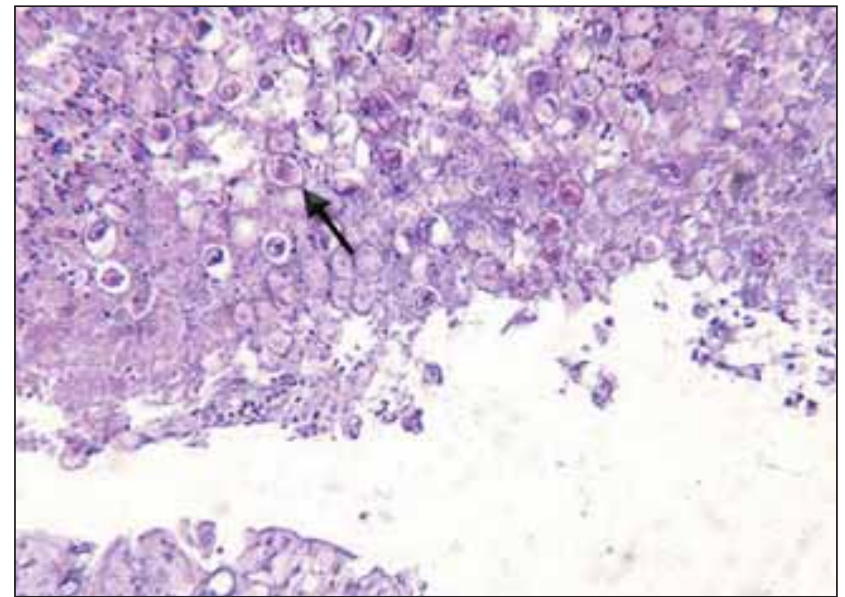

Figure-3: Group T5 showing complete destruction of intestinal villi with large number of megaschizonts (arrow) (H\&E $\times 400)$.

at a dose rate of $20 \mu \mathrm{g}$ on day 6 . However, previous report showed [12] elevated E. tenella sporozoite antibody levels with mean OD value of 0.72 to 0.94 in the same regimen in broiler chickens.

Histopathological examination: Histopathological examination (Figure-2 and 3) in chickens sacrificed at 5 days post challenge to assess the severity of infection revealed destruction of caecal epithelium in all groups, however, it was severe in group T3, moderate in group $\mathrm{T} 1$ and $\mathrm{T} 2$, and mild in $\mathrm{T} 4$ whereas the unimmunized infected T5 revealed severe destruction of villi and colonization of large number of megaschizonts [13].

Assessment of bodyweight gain: The mean weekly weight gain $(\mathrm{g})$ after challenge, at 56 days of age was high in T4 followed by T2, T3 and T1. The weight gains of all groups were found to be superior to that of unimmunized infected T5, however, inferior to that of unimmunized uninfected T5. Hence, the relative ratio of weight gain in the vaccinated birds was higher $(47.81 \%)$ in T4 than in T2, T3 and T1 whereas it was $26.2 \%$ in unimmunized infected T5. Similar findings were recorded previously [14] and [15]. However, these weight gains were not significantly high $(\mathrm{P}>0.05)$ when compared to unimmunized infected T5 but significantly $(\mathrm{P}<0.05)$ low when compared to unimmunized uninfected T5 (Table-2).

Assessment of lesion score: The mean lesion score 
Table-2: Mean bodyweight gain in broiler chickens

\begin{tabular}{|c|c|c|c|c|c|c|c|c|}
\hline \multirow{2}{*}{\multicolumn{3}{|c|}{ Treatment }} & \multicolumn{5}{|c|}{ Body weight in grams (Mean \pm SE) } & \multirow[b]{3}{*}{$56^{\text {th }}$ day } \\
\hline & & & \multicolumn{2}{|c|}{ Before challenge } & \multicolumn{3}{|c|}{ After challenge } & \\
\hline & $7^{\text {th }}$ day & $14^{\text {th }}$ day & $21^{\text {st }}$ day & $28^{\text {th }}$ day & $35^{\text {th }}$ day & $42^{\text {nd }}$ day & $49^{\text {th }}$ day & \\
\hline T1 & $\begin{array}{l}99.0^{\mathrm{a}} \pm 3.501 \\
\text { Total gain }-221 \\
\text { Relative ratio o }\end{array}$ & $\begin{array}{l}180.75^{a} \pm 3.788 \\
14.67^{a} \pm 40.426 \\
\text { f weight gain (\%) }\end{array}$ & $\begin{array}{l}232^{\mathrm{a}} \pm 12.465 \\
-26.92\end{array}$ & $314.7^{\mathrm{AB}} \pm 13.149$ & $503.67^{a} \pm 19.203$ & $509^{\mathrm{AB}} \pm 34.285$ & $300.44^{\mathrm{A}} \pm 16.404$ & $78.89^{\mathrm{a}} \pm 11.6$ \\
\hline T2 & $\begin{array}{l}94.75^{\mathrm{a}} \pm 5.208 \\
\text { Total gain - } 228 \\
\text { Relative ratio o }\end{array}$ & $\begin{array}{c}187.5^{\mathrm{a}} \pm 6.213 \\
34.50^{\mathrm{a}} \pm 74.407 \\
\text { f weight gain (\%) }\end{array}$ & $\begin{aligned} & 223.25^{\mathrm{a}} \pm 8.079 \\
- & 47.2\end{aligned}$ & $344.08^{B} \pm 14.787$ & $458.44^{\mathrm{a}} \pm 15.102$ & $506.22^{\mathrm{AB}} \pm 9.24$ & $326.13^{\mathrm{A}} \pm 14.381$ & $142.5^{\mathrm{a}} \pm 65.568$ \\
\hline T3 & $\begin{array}{l}90.00^{\mathrm{a}} \pm 2.733 \\
\text { Total gain - } 224 \\
\text { Relative ratio o }\end{array}$ & $\begin{array}{l}191.92^{\mathrm{a}} \pm 3.702 \\
41.67^{\mathrm{a}} \pm 67.333 \\
\text { f weight gain (\%) }\end{array}$ & $\begin{array}{r}244.5^{a} \pm 9.865 \\
-34.28\end{array}$ & $270.92^{\mathrm{A}} \pm 10.39$ & $502.44^{\mathrm{a}} \pm 12.845$ & $425.00^{\mathrm{A}} \pm 21.016$ & $420.00^{\mathrm{B}} \pm 27.689$ & $101.67^{\mathrm{a}} \pm 63.278$ \\
\hline T4 & $\begin{array}{l}101.83^{\mathrm{a}} \pm 1.934 \\
\text { Total gain - 234 } \\
\text { Relative ratio o }\end{array}$ & $\begin{array}{c}183.25^{\mathrm{a}} \pm 4.277 \\
42.50^{\mathrm{a}} \pm 42.483 \\
\text { f weight gain (\%) }\end{array}$ & $\begin{aligned} & 254.5^{\mathrm{a}} \pm 12.381 \\
- & 47.81\end{aligned}$ & $310.25^{\mathrm{AB}} \pm 11.963$ & $449.00^{a} \pm 36.315$ & $584.63^{\mathrm{B}} \pm 9.809$ & $306.63^{\mathrm{A}} \pm 17.765$ & $148.00^{\mathrm{a}} \pm 4.751$ \\
\hline $\mathrm{T} 5 \mathrm{U}$ & $\begin{array}{l}\text { infected } \\
100.17^{\mathrm{a}} \pm 6.478 \\
\text { Total gain - } 251 \\
\text { Relative ratio o }\end{array}$ & $\begin{array}{c}176.33^{\mathrm{a}} \pm 6.627 \\
18.83^{\mathrm{b}} \pm 38.704 \\
\text { f weight gain (\%) }\end{array}$ & $\begin{array}{l}256.33^{\mathrm{a}} \pm 11.546 \\
-100.0\end{array}$ & $363.33^{B} \pm 16.382$ & $405.50^{\mathrm{a}} \pm 11.337$ & $595.33^{B} \pm 28.527$ & $289.17^{\mathrm{A}} \pm 29.956$ & $332.67^{b} \pm 12.521$ \\
\hline $\mathrm{T} 5 \mathrm{ln}$ & $\begin{array}{l}\text { ected } \\
97.5^{\text {a }} \pm 3.978 \\
\text { Total gain - } 227 \\
\text { Relative ratio o }\end{array}$ & $\begin{array}{l}177.13^{\mathrm{a}} \pm 6.134 \\
78.20^{\mathrm{a}} \pm 85.418 \\
\text { f weight gain (\%) }\end{array}$ & $\begin{aligned} & 263.50^{\mathrm{a}} \pm 7.023 \\
&- 26.2 \\
&\end{aligned}$ & $354.75^{\mathrm{B}} \pm 14.529$ & $412.00^{\mathrm{a}} \pm 14.561$ & $567.50^{\mathrm{B}} \pm 9.839$ & $331.00^{\mathrm{A}} \pm 15.24$ & $78.33^{a} \pm 15.24$ \\
\hline
\end{tabular}

*Row-wise mean $( \pm S E)$ with different superscript (pqr..) differs significantly $(P<0.05)$, mean bearing 'upper case' superscript in a row is highly significant $(P<0.01)$. *Column- wise mean $( \pm S E)$ with different superscript (abc...) differs significantly $(P<0.05)$, mean bearing 'upper case' superscript in a column is highly significant $(P<0.01)$.

was lower in $\mathrm{T} 4(2.5 \pm 0.22)$ than in $\mathrm{T} 2(2.83 \pm 0.17), \mathrm{T} 1$ $(3.33 \pm 0.33)$ and $\mathrm{T} 3(3.00 \pm 0.45)$ when compared to unimmunised infected T5 (3.33 \pm 0.33$)$, indicating a moderate performance and partial protection by the sporozoites. However, there was no significant difference in the mean lesion score of all groups administered with the sporozoites $(\mathrm{P}>0.05)$. This finding is in agreement with previous reports $[16,17]$.

Assessment of oocyst output: The mean oocyst output in faeces (x10 $\left.0^{3} \mathrm{OPG}\right)$ was low in the group T4 (100.3 \pm 45.72) followed by $\mathrm{T} 2(128.3 \pm 53.25), \mathrm{T} 3(139.2 \pm$ $57.99)$ and $\mathrm{T} 1 \quad(145.3 \pm 55.09)$ in comparison with unimmunised infected T5 (205.5 \pm 75.73$)$. The mean OPG between the vaccinated groups was not significant $(\mathrm{P}>0.05)$, however, the mean OPG of $\mathrm{T} 4$ was significantly lower $(\mathrm{P}<0.05)$ than that of unimmunised infected T5. This finding is in agreement with Ziomko et al. [16].

\section{Conclusion}

It is concluded that, immunization with E. tenella specific sporozoites by parenteral administration in broiler chickens of less than a week old resulted in an early but partial protective immune response (IgG) against caecal coccidiosis with a mean bodyweight gain, mean lesion score and faecal oocyst output superior to the unimmunized infected controls.

\section{Authors' contributions}

SS and KMP planned and designed the experiment. SS performed the experiment. TJH, PS and GS drafted and revised the manuscript. All authors read and approved the final manuscript.

\section{Acknowledgements}

The authors are grateful to the Tamil Nadu Veterinary and Animal Sciences University, Chennai, Tamil Nadu, India for providing necessary financial assistance to carry out this research programme. The authors are also thankful to the Dean of Veterinary College and Research Institute, Namakkal, Tamil Nadu, India for providing immense support and necessary facilities to carry out this research work.

\section{Competing interests}

The authors declare that they have no competing interests.

\section{References}

1. Economic survey-2008-09. (2009) http://indiabudget.nic. in/es 200809/chapt2009/ chap72.pdf. Accessed 10-10-2013.

2. Kitandu, A. and Juranova, R. (2006) Review Article: Progress in Control Measures for Chicken Coccidiosis. Acta Vet. Brno., 75:265-276.

3. Banfield, M.J., Kwakkel, R. P., Groenevedld, M., Ten Doeschate, R.A. and Forbes, J.M. (1999) Effects of whole wheat substitution in broiler diets and viscosity on a coccidial infection in broilers. Brit. Poultry. Sci., 40: 58-59.

4. Lei Zhanga, Liping Ma, Renqiang Liu, Yunfei Zhang, Shouping Zhang, Chunmei Hu, Meng Song, Jianping Cai and Ming Wang. (2012) Eimeria tenella heat shock protein 70 enhances protection of recombinant microneme protein MIC2 subunit antigen vaccination against $E$. tenella challenge. Vet. Parasitol., 188: 239-246.

5. Sathish, K., Sriraman, R., Mohana Subramanian, R., Hanumantha Rao, N., Balaji Kasa, Jagan Donikeni, Lakshmi Narasu, M. and Srinivasan, V.A. (2012) Plant expressed coccidial antigens as potential vaccine candidates in protec- 
ting chicken against coccidiosis. Vaccine, 30: 4460-4464.

6. Vermeulen, A. N., Schaap, D. C. and Schetters, T. P. M. (2001) Control of coccidiosis in chickens by vaccination. Vet Parasitol., 100:13-20.

7. Liu, Y., Zheng, J., Li, J., Gong, P. and Zhang, X. (2013) Protective immunity induced by a DNA vaccine encoding Eimeria tenella rhomboid against homologous challenge. Parasitol.Res., 112:252-257.

8. Constantinoiu, C.C., Molloy, J.B., Jorgensen, W.K. and Coleman, G.T. (2007) Development and validation of an ELISA for detecting antibodies to Eimeria tenella in chickens. Vet. Parasitol., 150:306-313.

9. Constantinoiu, C.C., Molloy, J. B., Jorgensen, W.K. and Coleman, G. T. (2008) Antibody response against endogenous stages of an attenuated strain of Eimeria tenella. Vet. Parasitol., $154: 193-204$.

10. Hasbullah, T., Nakamura, H., Kawaguchi, Y., Nakai and Ogimoto, K. (1992) Detection of serum antibodies in Eimeria tenella infected chickens by enzyme linked immunosorbent assay (ELISA) with merozoites and oocysts antigens. J. Vet. Med. Sci., 54:201-206.

11. Kiani, R. and Farhang, H. H. (2008) Development of Elisa test for serological diagnosis of coccidial infections and studying of resistance against coccidiostats based on flock history. Asian J. BioSci., 1:77-83.

12. Smith, N. C., Bucklar, H., Muggli, E., Hoop, R. K., Gottstein, B. and Eckert, J. (1993) Use of IgG- and IgM-specific ELISAs for the assessment of exposure status of chickens to Eimeria species. Vet. Parasitol., 51:13-25.

13. Patra, G., Ayub, M., Ali, Kh. Victoria Chonu, Jonathan, L., Joy, L., Prava, M., Ravindran, R., Das, G. and Inatombi Devi, L. (2010) PCR based diagnosis of Eimeria tenella infection in broiler chicken. Int. J. Poultry. Sci., 9:813-818.

14. Conway, D.P., McKenzie, M., Elizabeth and Dayton, A.D. (1990) Relationship of coccidial lesion scores and weight gain in infections of Eimeria acervulina, E. maxima and E. tenella in broilers. Avian Pathol., 19: 489 - 496.

15. Kawazoe, U. (2000) Coccidiose. In: A. Berchieri, M. Mcari, editors. Doenca das aves. Campinas: Facta, p391-405.

16. Ziomko, I., Karamon, J., Cencek, T., Gornowicz, E., Skoracki, A. and Ashash, U. (2005) Prevention of broiler chick coccidiosis using the inactivated subunit vaccine coxabic $^{\circledR}$. B. Vet. I. Pulawy, 49, 299-302.

17. Geriletu, B., Xua, L., Xurihuab and Li, X. (2011) Vaccination of chickens with DNA vaccine expressing Eimeria tenella MZ5-7 against coccidiosis. Vet. Parasitol., 177:6-12.

\section{$* * * * * * * *$}

